\title{
INICIAÇÃO À PESQUISA NO ENSINO SUPERIOR: DESAFIOS DOS DOCENTES NO ENSINO DOS PRIMEIROS PASSOS
}

\section{Initiation into Higher Education Research: professors' challenges in teaching the first steps}

\author{
Derli Juliano Neuenfeldt ${ }^{1}$ \\ Rogério José Schuck ${ }^{2}$ \\ Angélica Munhoz ${ }^{3}$
}

\author{
Juliana Mittelstadt ${ }^{4}$ \\ Tânia Micheline Miorando ${ }^{5}$ \\ Ronaldo Rochenback ${ }^{6}$
}

\begin{abstract}
Resumo: Esta pesquisa descritiva teve por objetivo compreender o modo como se dá a iniciação à pesquisa no Ensino Superior a partir dos professores que atuam com as disciplinas relacionadas a essa área. As informações foram coletadas mediante a realização de sete entrevistas semiestruturadas com professores da UNIVATES. Constataram-se três preocupações centrais: a) trabalhar com os alunos a compreensão do que é ciência e do que é pesquisa; b) ensinar normativas de escrita (ABNT), métodos e técnicas de pesquisa; e c) articular a pesquisa com o campo de atuação do acadêmico. Conclui-se que há necessidade de se aprofundar a compreensão de pesquisa e de ciência dos alunos, e que os cursos e professores das outras disciplinas assumam, conjuntamente, a responsabilidade pela formação científica e ética.

Palavras-chave: Iniciação à pesquisa. Ensino Superior. Docência.

Abstract: The aim of this descriptive research was to understand the way in which the initiation in Higher Education is done as professors who work with the related subjects in this area. The information was collected through seven semi-structured interviews with professors of UNIVATES. Three main worries were detected: a) work with students on the comprehension of what is science and what is research; b) teaching normative writing (ABTN), methods and research techniques; and c) the link between the research and the actual field of the academic student. The results show the need to deepen the students' comprehension of research and science, and that the courses and professors of other subjects should assume, conjunctly, the responsibility for scientific and ethical formation.
\end{abstract}

Keywords: Research initiation. Higher Education. Teaching.

${ }^{1}$ Graduado em Educação Física, mestre em Ciência do Movimento Humano. Docente, Curso de Educação Física, Centro Universitário UNIVATES-RS. Lajeado, RS, Brasil. < derlijul@univates.br>

${ }^{2}$ Graduado em Filosofia, doutor em Filosofia. Docente, Centro de Ciências Humanas e Jurídicas, UNIVATES.

Lajeado, RS, Brasil. <rogerios@univates.br>

${ }^{3}$ Graduada em Pedagogia, doutora em Educação. Docente, Centro de Ciências Humanas e Jurídicas, UNIVATES. Lajeado, RS, Brasil. <angelicavmunhoz@gmail.com>

${ }^{4}$ Graduada em Pedagogia. Bolsista de Iniciação à Pesquisa. UNIVATES. Lajeado, RS, Brasil.

$<$ julianamittel@msbnet.com.br>

${ }^{5}$ Graduada em Educação Especial, mestre em Educação. Docente, UNIVATES. Lajeado, RS, Brasil.

<tmiorando@gmail.com>

${ }^{6}$ Graduando em Educação Física. Bolsista de Iniciação à Pesquisa. UNIVATES. Lajeado, RS, Brasil. rrockenbach@universo.univates.br

${ }^{1}$ Rua Avelino Tallini, 171

Bairro Universitário - Lajeado, RS

$95.900-000$ 
Neuenfeldt, D. J. et al.

\section{Introdução}

A universidade se caracteriza por valorizar o conhecimento científico. No entanto, conceituar o que é ciência não é tarefa fácil. Para Alves (1983), o conhecimento científico é o senso comum refinado. Já, para Oliveira (1985), é o conhecimento que passou por um método próprio e é submetido a controles que garantem uma probabilidade maior de ser verdadeiro. A existência de diferentes paradigmas faz dessa temática campo fértil de discussão.

No Centro Universitário UNIVATES, a preocupação com o conhecimento científico encontra-se expressa na Missão Institucional: "Gerar, mediar e difundir o conhecimento técnico-científico e humanístico, considerando as especificidades e as necessidades da realidade regional, inseridas no contexto universal, com vistas à expansão contínua e equilibrada da qualidade de vida" (UNIVATES, 2009, p. 2). Assim, despertou o interesse em investigar o processo de iniciação à pesquisa nos cursos de graduação dessa instituição.

Não iremos falar, no entanto, dos alunos que possuem o privilégio ou que conquistaram, por mérito, a possibilidade de serem bolsistas de iniciação à pesquisa e atuam em projetos de autoria de docentes/pesquisadores, nem do processo de elaboração do Trabalho de Conclusão de Curso. Iremos falar do processo de iniciação à pesquisa que ocorre nas disciplinas dos cursos e que são obrigatórias a todos os alunos do Ensino Superior, que podem ser denominadas de diferentes formas, tais como: Metodologia Científica, Iniciação à Pesquisa, Métodos e Técnicas de Pesquisa, entre outras. Nelas os primeiros passos são dados.

Dessa forma, ao nos remetermos aos cursos de graduação, nos perguntamos: Como se dá o processo de iniciação à pesquisa nos cursos de graduação? O que os professores que ministram as disciplinas relacionadas à iniciação têm priorizado em suas aulas? Com quais desafios eles têm se deparado?

Com base nessas inquietações, estabelecemos como objetivo desta pesquisa compreender o modo como se dá a iniciação à pesquisa no Ensino Superior, a partir dos professores que atuam com as disciplinas relacionadas a essa área de conhecimento.

Este estudo se justifica pelo fato de poder contribuir para identificar como a instituição tem trabalhado a iniciação à pesquisa com os alunos que chegam do Ensino Médio, assim como dificuldades e progressos em relação à temática. Dessa forma, acredita-se que este estudo possa contribuir com dados e reflexões que podem vir a auxiliar a melhoria do ensino nas disciplinas relacionadas à iniciação científica.

\section{Metodologia}

Esta pesquisa caracteriza-se como descritiva, de cunho qualitativo. Para Minayo (2004), a pesquisa qualitativa responde a questões muito particulares. Ela trabalha com um universo de significados, motivos, aspirações, crenças, valores e atitudes, e isso se refere a um espaço mais profundo das relações, dos processos e dos fenômenos, os quais não podem ser quantificados. Também Triviños (1987, p. 128) destaca que a pesquisa qualitativa é essencialmente descritiva, pois "as descrições dos fenômenos estão impregnadas dos significados que o ambiente lhe outorga, e como aquelas são produto de uma visão subjetiva, rejeita toda a expressão quantitativa, numérica, toda medida". Além disso, conforme Triviños (1987), a maioria dos 
Iniciação à Pesquisa no Ensino Superior: desafios...

estudos no campo da educação é de natureza descritiva, tendo como foco principal conhecer o desejo de uma comunidade, seus traços característicos, seus problemas etc.

\section{Participantes do estudo}

O Centro Universitário UNIVATES/RS possui os cursos distribuídos em quatro centros: Centro de Ciências Exatas e Tecnológicas (CETEC), Centro de Gestão Organizacional (CGO), Centro de Ciências Biológicas e da Saúde (CCBS) e Centro de Ciências Humanas e Jurídicas $(\mathrm{CCHJ})$. Esses totalizam 44 cursos de graduação ou superior sequencial ou de tecnologia.

Optou-se por buscar informações para atender o objetivo do estudo junto aos professores da UNIVATES que atuam nas disciplinas relacionadas à iniciação à pesquisa. Em relação às disciplinas, encontramos 11 denominações diferentes. A seguir, apresentamos as disciplinas e os respectivos cursos que as adotam em suas matrizes curriculares: 1) Experimentos e Pesquisa em Design: Design de Produtos; Design Gráficos; 2) Pesquisa Operacional: Jornalismo; Publicidade e Propaganda; Relações Públicas; 3) Metodologia e Técnica de Pesquisa: Ciências Contábeis; Relações Internacionais; Secretariado Executivo; 4) Metodologia da Pesquisa Aplicada à Fisioterapia: Fisioterapia; 5) Pesquisa em Psicologia I: Psicologia; 6) Pesquisa em Educação: Pedagogia; História; Ciências Exatas; Letras; 7) Métodos e Técnicas de Pesquisa em Educação: Educação Física - Bacharelado; Educação Física - Licenciatura; 8) Introdução à Pesquisa: Direito; Farmácia; Nutrição; Biomedicina; Ciências Biológicas - Bacharelado; Ciências Biológicas - Licenciatura; 09) Pesquisa em Administração: Administração de Empresas; Análise de Sistemas; Comércio Exterior; Gestão em Cooperativas; Gestão em Turismo; Negócios Agroindustriais; Ciências Econômicas; 10) Metodologia Científica e Tecnológica: Engenharia da Produção; Engenharia Ambiental; Engenharia Civil; Engenharia da Computação; Engenharia de Alimentos; Engenharia Mecânica; Sistema de Informações; e 11) Metodologia da Pesquisa em Enfermagem: Enfermagem.

Nas disciplinas e cursos acima mencionados, atuam 14 professores. Destes, sete foram entrevistados. De três Centros, entrevistaram-se dois professores de cada e, no outro, um professor, totalizando sete. Assim, obteve-se representação das diferentes áreas de conhecimento. Também se levou em conta a disponibilidade dos professores em participar da pesquisa. Assim, a escolha dos professores se deu de forma deliberada e intencional, pois, de acordo com Gómez, Flores e Jiménez (1996), na pesquisa qualitativa as pessoas ou grupos não são selecionados ao acaso para completar uma amostragem de tamanho $n$. Escolhe-se uma a uma de acordo com a vontade do pesquisador, de maneira que atendam aos critérios ou atributos estabelecidos pelo pesquisador.

\section{Técnicas e procedimentos de coleta de informações}

Para o desenvolvimento deste estudo, foram coletadas informações mediante entrevistas semiestruturadas realizadas no segundo semestre de 2009. A entrevista semiestruturada, de acordo com Triviños (1987, p. 146), "parte de certos questionamentos básicos, apoiados 
Neuenfeldt, D. J. et al.

em teorias e hipóteses, que interessam à pesquisa, e que, em seguida, oferecem amplo campo de interrogativas, fruto de novas hipóteses que vão surgindo à medida que se recebem as respostas do informante".

Todos os entrevistados foram comunicados do objetivo do estudo, leram e assinaram o Termo de Consentimento Livre e Esclarecido, aprovado pelo Comitê de Ética da Univates.

As entrevistas foram agendadas e realizadas em local reservado. Foram gravadas, transcritas e entregues aos entrevistados para que pudessem ler e validar as informações. Eles também tiveram a liberdade para acrescentar ou excluir trechos de suas falas. A entrega aos informantes foi feita em cópia impressa ou via e-mail, buscando o recurso que o entrevistado considerasse mais cômodo.

No presente artigo, para se preservar a identidade dos participantes, utilizamos os seguintes códigos para os professores entrevistados: professor 1, 2, 3, 4, 5, 6 ou 7 .

\section{Análise das informações}

As informações obtidas foram estruturadas em categorias de análises, que, conforme Gomes (2004), significa agrupar elementos, ideias e expressões em torno de um conceito com características comuns, ou que se relacionam entre si. As categorias estabelecidas foram três: a) trabalhar a concepção do que é ciência e do que é pesquisa; b) ensinar normativas de escrita (ABNT), normas e técnicas de pesquisa, e c) articular a pesquisa com o campo de atuação do acadêmico.

Além disso, foi realizada a triangulação das informações obtidas nas entrevistas com o referencial teórico, sobretudo com Demo (2007), que defende a necessidade de se educar pela pesquisa e que este processo deve se iniciar na Educação Básica, com o estudo de Neuenfeldt et al. (2008) sobre a produção do conhecimento no Ensino Médio frente à presença das novas tecnologias de informação (Internet), e de Oliveira (2009), Booth, Colomb e Williams (2000), que escrevem sobre o papel da iniciação à pesquisa no Ensino Superior. A triangulação das informações, conforme Triviños (1987, p. 138), "tem por objetivo abranger a máxima amplitude na descrição, explicação e compreensão do foco em estudo".

\section{Análise e discussão dos resultados}

Com base na fala dos professores entrevistados, elaboramos três categorias em relação ao processo de iniciação à pesquisa. Essas preocupações podem estar presentes na fala de um mesmo professor ou separadamente. Elas podem ter mais ou menos ênfase de acordo com as características e o perfil de profissional que cada curso deseja formar. A seguir, passaremos a cada uma delas:

\section{a) Trabalhar a concepção do que é ciência e do que é pesquisa}

Os professores que atuam nas disciplinas de iniciação à pesquisa sentem dificuldade em relação à compreensão de pesquisa que os alunos trazem do Ensino Médio. Os professores 1 e 4 comentam: 
Iniciação à Pesquisa no Ensino Superior: desafios...

"Eu não vejo nenhuma diferença na minha formação com pesquisa que eu tive no 2. ${ }^{\circ}$ Grau com a formação dos alunos que eu estou recebendo do Ensino Médio, e eu terminei ele em 92. Então quer dizer que o aluno vem para a Universidade do mesmo jeito que en fui para a Universidade, sem saber absolutamente nada de pesquisa, o que é pesquisa, o que se faz em pesquisa, por que na Universidade a linguagem é cientifica [...]." (entrevista prof. 1)

"[...] na Escola Básica ele até é desafiado a pesquisar, mas não tem uma exigência quanto aos resultados da pesquisa. Então, quando se coloca a situação de pesquisa para o estudante já universitário, a tendência inicial é que ele reproduza toda a situação da escola. O que se coloca aí, como desafio do professor, é desconstruir uma imagem do que seja pesquisa, que eles trazem da Escola Básica, para poder reconstrui-la sobre outras condições. Isso é o que eu vejo de mais problemático". (entrevista prof. 4)

Para Oliveira (2001), o Ensino Superior, enquanto continuidade da Educação Básica, é responsável pela formação teórico-prática do aluno em áreas/subáreas específicas do conhecimento. Cabe a ele familiarizar o aluno com o referencial de base da área/subárea escolhida por este para estudo, dando condições de iniciar sua vida profissional e/ou seguir uma carreira acadêmica. Mas a iniciação científica do aluno não pode ser pensada somente a partir do Ensino Superior nem apenas por meio da pesquisa científica da qual ele participa sob orientação de um professor.

O professor 6 comenta que as dificuldades em relação ao desenvolvimento de trabalhos acadêmicos exigiram mudanças na forma de ministrar a disciplina:

\footnotetext{
"Os caras chegavam na disciplina, mas não sabiam se organizar para o trabalbo acadêmico. Eles simplesmente escreviam lá um trabalho feito em aula, uma resenha. Deixavam até as barbichas do caderno. Assim entregavam aquilo digitado. Não era formatado; era tudo uma loucurada. Eles copiavam as coisas e não colocavam os autores, as fontes, e achavam que não precisavam, porque eles pensavam conforme os autores. Então o que que eu fiz: eu remodelei tudo. É introdução à pesquisa, introdução. Portanto, nós vamos começar a pesquisar, estudar o que é a pesquisa, como se busca [...]. Eu comecei a disciplina, partindo das concepcõoes que eles têm a respeito do que seja uma pesquisa [...]. Trabalho com eles a questão da autoria e de ética, que eu acho que é fundamental quando se faz. uma pesquisa, porque, copia, recorta e cola, que é isso que a gente vê adoidado, e é muito triste quando a gente vê um trabalho de um aluno que é um recorta, cola e copia."
}

Em pesquisa realizada com 373 alunos do $3^{\circ}$ ano do Ensino Médio dos municípios de Lajeado, Estrela, Arroio do Meio e Encantado, RS/BRA, em 2008, Neuenfeldt et al. (2008), ao investigarem o uso da Internet como fonte de pesquisa e como ela é utilizada para elaboração de trabalhos escolares, evidenciaram que: 
Neuenfeldt, D. J. et al.

[...] predomina tendência à reprodução do conhecimento, pois $9 \%$ deles falaram diretamente que copiam e colam e $52 \%$ que juntam diversos textos copiando e colando o que interessa, o que não difere muito. Ler e interpretar reescrevendo é citado por $14 \%$ e ler e escrever novo texto a partir das ideias apresentadas, por 21\%. (NEUENFELDT et al., 2008, p. 10)

Assim, podemos considerar que a preocupação dos professores que ministram as disciplinas de Iniciação Científica tem procedência, pois são dos municípios anteriormente mencionados de onde vem o maior número de alunos para estudar na UNIVATES. E a forma como a pesquisa tem sido desenvolvida no Ensino Médio é preocupante.

Para Demo (2007), educar pela pesquisa é um dos grandes desafios da Educação Básica. O fazer e refazer-se na e pela pesquisa é o que melhor distingue a educação escolar de outros tipos e espaços educativos, tais como: a família, a roda de amigos, o ambiente de trabalho etc. Esses outros espaços podem recorrer à pesquisa ocasionalmente, mas não com propriedade específica. No entanto, comenta o autor que a educação pela pesquisa supõe cuidados propedêuticos decisivos, no professor e no aluno. Um desses cuidados é que: "O professor deve orientar o aluno permanentemente para expressar-se de maneira fundamentada, exercitar o questionamento sempre, exercitar a formulação própria, reconstruir autores e teorias e cotidianizar a pesquisa" (DEMO, 2007, p. 34).

Em virtude da limitada compreensão de pesquisa dos alunos que vêm do Ensino Médio, em relação ao trabalho que desenvolvem, os professores 1 e 2 comentam a necessidade de se trabalhar com a compreensão do que é ciência e construir uma compreensão de pesquisa:

"[...] ela é realmente uma iniciação. A gente dá toda uma parte da Filosofia da Ciência, História da Ciência, o que é pesquisa, quais são as etapas da pesquisa [...]”. (entrevista prof. 1)

"A proposta é que o aluno tenha uma autoria, nessa iniciação à pesquisa, desde o tema. Não é só botar dentro dos padrões, com objetivos, e tal, questões norteadoras, metodologia, não é isso. É eles terem ferramentas para eles terem o percurso teórico deles, que é o que vai embasar a forma como eles vão chegar naquele lugar, para poder, nas informações que eles querem produzir, então o conbecimento. Para mim pesquisa é isso". (entrevista prof. 3)

É possível perceber que a preocupação está em desenvolver um aluno que seja consciente dos seus atos e responsável por eles. Por essas razões, os professores destacam aspectos para além dos aspectos técnicos e normativos e da elaboração de trabalhos acadêmicos, chegando a citar a necessidade de se trabalhar com a Filosofia da Ciência.

Nesse aspecto, cabe lembrar Chauí (2002, p. 18), que destaca que "o senso comum em nossa sociedade considera útil aquilo que dá prestígio, poder, fama e riqueza. Julga útil pelos resultados visíveis das coisas e das ações, identificando utilidade e a famosa expressão 'levar vantagem em tudo"'. No entanto, a autora comenta que: 
Iniciação à Pesquisa no Ensino Superior: desafios...

Se abandonar a ingenuidade e os preconceitos do senso comum for útil; se não se deixar guiar pela submissão às ideias dominantes e aos poderes estabelecidos for útil; se tentar compreender a significação do mundo, da cultura, da história for útil; se conhecer o sentido das criações humanas nas artes, nas ciências e na política for útil; se dar a cada um de nós e à nossa sociedade os meios para serem conscientes de si e de suas ações numa prática que deseja a liberdade e a felicidade para todos for útil, então podemos dizer que a Filosofia é o mais útil de todos os saberes de que os seres humanos são capazes. (CHAUÍ, 2002, p. 18)

Assim, com base em Chauí (2002), percebemos que os professores que atuam nas disciplinas de iniciação à pesquisa sentem a necessidade de que essas disciplinas deem subsídios para o aluno compreender o que é pesquisa. Isso observamos nos relatos abaixo:

"É apresentar para ele diferentes concepcões, diferentes perspectivas teórico-metodologicas do procedimento de pesquisa [...] para que o sujeito possa compreender este início da pesquisa, mas só o início mesmo, só a arrancada, tá, nada tão aprofundado, como talvez em outros niveis de ensino a gente possa pensar esta disciplina". (entrevista, prof. 5)

"[...] o aluno se dá conta de que ele não vai achar o tema que ele quer pesquisar pronto, porque, senão, não tem por que tu pesquisares. Ele tem que construir esse tema, ou seja, ele tem que ler vários artigos para poder formar o tema do qual ele tá falando. Isso é que vai distinguir ele de pesquisador, e não mero copiador. Isso eu chamo de autoria. Assim, esse exercício ele é difícil, porque os alunos não estão muito acostumados a pensar". (entrevista prof. 3)

Conforme Demo (2007, p. 16), “a educação não é só ensinar, instruir, treinar, domesticar, é, sobretudo, formar a autonomia crítica e criativa do sujeito histórico competente". Também Luckesi, Barreto e Cosma (2003) comentam que o conhecimento liberta o sujeito porque lhe dá independência e autonomia. Essa independência apresenta-se no sentido de podermos buscar o que nos interessa, de seguirmos por caminhos que antes não conseguiríamos; e autonomia para fazer escolhas, ter opinião e base para desconfiar do que parece ser incerto.

Nesse processo de autonomia, cabe ressaltar a importância da leitura. A falta dela pode dificultar o processo de iniciação à pesquisa e, consequentemente, o de escrita. Os professores destacam:

"[...] eles estão chegando lendo muito pouco. A maior dificuldade que eu vejo nesta disciplina é o sujeito ler; e ler é fundamental para a base interpretativa, para a elaboração das técnicas iniciais, de aprofundamento teórico. Tem sido esta perspectiva, isto que tem limitado consideravelmente, pouca leitura dos estudantes [...]". (entrevista prof. 5) 
Neuenfeldt, D. J. et al.

"[...] só escreve aquele sujeito que lê. Então isso é uma coisa que eu converso bastante com os alunos. Até tem um autor que diz assim: "nós somos aquilo que lemos", $e$ isso bate em mim também, poxa. Se nós somos tudo aquilo que lemos, quantos livros eu li este ano? Será que eu li algum? Quantos capitulos eu li?Né, então eu sempre faço os alunos pensarem a respeito disto [...]". (entrevista prof. 6)

\section{b) Ensinar normativas de escrita ( $\mathrm{ABNT})$, métodos e técnicas de pesquisa}

Uma segunda preocupação que aparece entre os professores que ministram as disciplinas de iniciação à pesquisa diz respeito às questões técnicas e normativas da elaboração de trabalhos acadêmicos. Ao analisarmos as falas deles, percebe-se que elas são ensinadas, que acompanham a disciplina, mas a disciplina não se limita a essas questões:

"[...] eu trabalho o que é uma pesquisa e os passos de um trabalho acadêmico, como é que se organiza um trabalho acadêmico, e por que se organiza desse jeito, desde os primeiros passos, como introdução, capa, folha de rosto, até a formatação e normas da $A B N T$. Só que eu não perco tempo da minha aula ensinando normas da ABNT, porque é só ir lá e abrir a página tal do manual da UNIVATES que explica o que é, mas en mostro para os alunos onde encontrar essas normas a respeito disso [...]". (entrevista prof. 6)

"[...] os professores pedem muito que a gente dê as normas, técnicas de apresentação de trabalhos para os alunos. Então a gente também passa isso. Quando possivel, a gente revê também alguma coisa da escrita. A forma de escrever, a linguagem acadêmica. Apresentação oral dos trabalhos, como se faz, como se organiza, a introdução à pesquisa, como se faz um trabalbo acadêmico [...]". (entrevista prof. 1)

Uma preocupação que passa por uma ordem técnica, mas também ética, e que pode ter consequências no campo legal é o plágio. De ordem técnica, pois, é necessário ensinar a escrever, a fazer uso das diferentes fontes de forma correta. Ética, na medida em que se sabe fazer uso das fontes, mas se usa da cópia conscientemente. Ao serem perguntados se têm encontrado plágio na disciplina, os professores respondem:

"Sim, de forma, inclusive, absolutamente, como dizer, escancarada. Coisa da pessoa botar um nome na internet e o primeiro texto que aparece ela copia inteiro, nem sabe o conteúdo, nem nada. É preciso dar alguns passos dentro da pesquisa e o primeiro passo é saber fazer o uso de paráfrases, ou seja, você tem que ter condição de ler um texto e escrever com as próprias palavras". (entrevista prof. 4)

"Pouco, mas sim. O plágio na disciplina, e isso é uma interpretação minha, ocorre quando o sujeito é pressionado em relação a uma avaliação. Ele tem que entregar algo em determinado tempo. Ele se atrapalha na administração do próprio tempo. E ele opta pela via mais fácil para responder a demanda, e ai ele acaba fazendo, tendo um deslize moral e, por que não, ético [...]". (entrevista prof. 5) 
Iniciação à Pesquisa no Ensino Superior: desafios...

O professor 2 aponta que o perfil de aluno da UNIVATES, aluno/trabalhador, pode também dificultar o desenvolvimento da proposta da disciplina que ministra:

"[...] outro problema que a gente vislumbra é essa questão de o aluno não ter esse tempo suficiente para fazer a pesquisa. Os nossos alunos, na grande maioria, são alunos trabalhadores".

A presença do plágio tem sido identificada com mais frequência na escrita do referencial teórico. Uma forma adotada pelos professores de fazer com que o aluno se engaje no processo de pesquisa é desafiá-lo a elaborar propostas a partir da sua própria realidade:

"Sim, a gente às vezes encontra alguma coisa com relação principalmente com o referencial teórico [...]. Agora, quando precisa descrever um problema, os objetivos, a justificativa do seu trabalho, o problema em si e a empresa, não tem como ele plagiar, porque cada trabalho é um trabalho diferenciado [...]." (entrevista prof. 2)

"É que, assim, é muito criativo, entendeu? Não tem muita cópia. O negócio é mais desenvolver mesmo, criar'. (entrevista prof. 7)

Para Demo (2007), devemos motivar os alunos para que façam interpretações próprias, iniciando a elaboração. "Uma coisa é manejar textos, copiá-los, decorá-los e reproduzilos. Outra é interpretá-los com alguma autonomia, para saber fazê-los e refazê-los" (DEMO, 2007, p. 23).

\section{c) Articular a pesquisa com o campo de atuação do acadêmico}

Uma terceira preocupação identificada nas propostas das disciplinas de iniciação à pesquisa diz respeito à aproximação da investigação com o atual ou futuro campo de atuação do acadêmico. Isso está expresso nas falas abaixo:

"[...] eu penso que trabalhar com situações problemas empresariais, onde os alunos vislumbram na empresa quais os problemas da matemática, e trazem isso para a Academia, é uma forma que ele tem de realizar a pesquisa. Então ele trazpara a Academia os problemas. A gente resolve esses problemas, e ele volta para a empresa com eles e com possibilidades de ações, de estratégias que possam melhorar também a produtividade, o rendimento, a redução de custos, a maximização de lucros". (entrevista prof. 2)

"Bom, por ser experimentos de pesquisa, eu peço muita coisa assim que eles têm que buscar primeiro referências bibliográficas. E, a partir das referências bibliográficas, eu sempre faço um trabalho prático. Essa é sempre uma ideia. Em todas as disciplinas, eu procuro conciliar a teoria e a prática. Isso praticamente em $90 \%$ das minhas disciplinas. Tá, esta daqui, a pesquisa, foi mais uma pesquisa de campo, assim, porque é muito experimental esta disciplina". (entrevista, prof. 7) 
Neuenfeldt, D. J. et al.

De acordo com Booth, Colomb e Williams (2000), para o pesquisador iniciante, a pesquisa o ajudará a compreender o assunto estudado e, a longo prazo, as técnicas de pesquisa e redação o capacitarão para trabalhar por conta própria. Os autores afirmam que: "Coletar informações, organizá-las de modo coerente e apresentá-las de maneira confiável e convincente são habilidades indispensáveis na "Era da Informação"' (BOOTH; COLOMB; WILLIAMS, 2000, p. 3).

Além disso, a pesquisa possibilita a construção de um profissional capaz de investigar o seu próprio campo de atuação. O professor 4 diz:

\begin{abstract}
"[...] estamos trabalhando fundamentalmente com a ideia de que o pesquisador se constrói, se forma, pela experiência. Alias é um paradigma educacional meu, né, de ensino. Então, trabalhei fundamentalmente uma das competências previstas no projeto do curso, que é a ideia da articulação entre ensino e pesquisa, professor como pesquisador, e o trabalho todo se desenvolven a partir de experiências com pesquisa, quando o arcabouço conceitual é necessário para compreender a pesquisa e realizar a pesquisa. Foram construidos pela turma a partir de pesquisas. A própria turma que fez a pesquisa bibliográfica, experimentou pesquisa empírica quantitativa".
\end{abstract}

Para Demo (2007), é necessário superar a visão unilateral de considerar pesquisa apenas estágios sofisticados, representados pelos produtos solenes do mestre ou doutor. A pesquisa precisa ser internalizada como atitude cotidiana, mas não é qualquer coisa, seu distintivo mais próprio é o questionamento reconstrutivo. "Por 'questionamento', compreende-se a referência à formação do sujeito competente, no sentido de ser capaz de, tomando consciência crítica, formular e executar projeto próprio de vida no contexto histórico" (DEMO, 2007, p. 10.). Aí, inclui-se a passagem de objeto para sujeito.

\title{
Conclusão
}

Ao finalizarmos este estudo, percebemos que o processo de iniciação à pesquisa ocorrido nas disciplinas dos diferentes cursos enfatiza três aspectos: a) trabalhar a compreensão do que é ciência e do que é pesquisa; b) ensinar normativas de escrita (ABNT) e métodos e técnicas de pesquisa; e c) articular a pesquisa com o campo de atuação do acadêmico.

A ênfase dada a cada um deles é diferenciada em cada curso, pois o professor busca contemplar o perfil de egresso que se quer. No entanto, percebe-se, entre os professores, uma preocupação em relação à compreensão de ciência e de pesquisa com a qual os alunos estão se deparando no Ensino Superior. Dessa forma, as disciplinas necessitam dar conta de questões da Filosofia da Ciência, questões normativas e técnicas e, ainda, conciliar teoria e prática. Isso representa um grande desafio para esses professores que, muitas vezes, possuem apenas uma disciplina de sessenta ou trinta horas aula.

Nesse sentido, buscando melhorar ou dar continuidade ao trabalho iniciado nessas disciplinas, é possível apresentar, no momento, duas sugestões: a) ter disciplinas que ampliem as discussões éticas. Neste caso, uma disciplina obrigatória e comum a todos os cursos, tal 
Iniciação à Pesquisa no Ensino Superior: desafios...

como Filosofia da Ciência; b) que cada curso, em todas as disciplinas, assuma a responsabilidade pela continuidade da formação científica e ética. Isso demanda grande articulação entre os professores e destaque nos Projetos Pedagógicos dos cursos.

Há preocupação dos professores no sentido de que o aluno venha a aprender a "andar com as próprias pernas", rompendo com o ensino tradicional (bancário), pois se deseja que a pesquisa seja internalizada no seu cotidiano profissional. A autonomia e a autoria são competências almejadas pelos professores, solidificadas com uma formação ética. Contudo, conforme Oliveira (2001, p. 14), se o modelo de ensino for pautado pela transmissão-recepção, não podemos esperar que "nossos alunos produzam, em seus trabalhos acadêmicos, uma articulação de um discurso científico coerente, pautado pelo diálogo entre diferentes autores, pela multirreferencialidade, inovador, cujo caminho sequer iniciamos na condução das atividades da prática acadêmica".

Enfim, finalizamos com Demo que sintetiza o que esperamos em relação ao processo de iniciação à pesquisa:

A pesquisa inclui sempre a percepção emancipatória do sujeito que busca fazer e fazer-se oportunidade, à medida que começa e se reconstitui pelo questionamento sistemático da realidade. Incluindo a prática como componente necessário da teoria, e vice-versa, englobando a ética dos fins e valores. (DEMO, 2007, p. 8)

\section{Referências}

ALVES, R. Filosofia da ciência: introdução ao jogo e suas regras. 4. ed. São Paulo: Brasiliense, 1983.

BOOTH, W. C.; COLOMB, G. G.; WILliAMS, J. M. A arte da pesquisa. São Paulo: Martins Fontes, 2000.

CHAUÍ, M. Convite à filosofia. 12. ed. São Paulo: Ática, 2002.

DEMO, P. Educar pela pesquisa. 8. ed. Campinas: Autores Associados, 2007.

GOMES, R. A análise de dados em pesquisa qualitativa. In.: MINAYO, M. C. S. (Org.).

Pesquisa social: teoria, método e criatividade. Petrópolis: Vozes, 2004. p. 67-80.

GÓMEZ, G. R.; FLORES, J. G.; JIMÉNEZ, E. G. Metodología de la investigación cualitativa. Maracena: Ediciones Aljibe, 1996.

LUCKESI, C.; BARRETO, E.; COSMA, J. Fazer universidade: uma proposta metodológica. 13. ed. São Paulo: Cortez, 2003.

MINAYO, M. C. S. Ciência, técnica e arte: o desafio da pesquisa social. In: (Org.)

Pesquisa social: teoria, método e criatividade. Petrópolis: Vozes, 2004. p. 9-28. 
Neuenfeldt, D. J. et al.

NEUENFELDT, D. J. et al. A cibercultura e os alunos do ensino médio: apontamentos e reflexões. Lecturas: Educación Física y Deportes. Revista Digital, Buenos Aires, v. 13, n. 126, p. 1-13, 2008. Disponível em: <http://www.efdeportes.com/efd126/a-ciberculturae-os-alunos-do-ensino-medio.htm>. Acesso em: 12 fev. 2008.

OLIVEIRA, L. O que é ciência? São Paulo: Brasiliense, 1985.

OLIVEIRA, L. C. V. Iniciação à pesquisa no ensino superior: o novo e o velho espírito científico nas atividades acadêmicas. In: Reunião Anual da ANPED, 24., 2001, Caxambu.

Anais... Caxambu, 2001. p. 1-15. Disponível em: <http://www.anped.org.br/reunioes/24/ T1181081976681.doc >. Acesso em: 17 mar. 2011.

TRIVIÑOS, A. N. S. Introdução à pesquisa em ciências sociais: a pesquisa qualitativa em educação. São Paulo: Atlas, 1987.

UNIVATES. Plano de Desenvolvimento Institucional: PDI 2010-2014. Lajeado:

Univates, 2009. Disponível em: <http://www.univates.br/files/files/univates/catalogo/

PDI_Resumo.pdf $>$. Acesso em: 1 mar. 2010.

Artigo submetido em junho de 2010 e aceito em fevereiro de 2011. 